\title{
Ability of nifedipine to prolong parturition in rats
}

\author{
T. S. Tracy* and C. D. Black $\dagger$ \\ Department of Pharmacy Practice, School of Pharmacy and Pharmacal Sciences, Purdue \\ University, West Lafayette, IN 47906, USA
}

\begin{abstract}
Summary. Rats were randomly assigned to treatments: (i) no surgery control; (ii) saline control; (iii) $0.25,0.5,1.0$ or $2.0 \mu \mathrm{g}$ nifedipine $\mathrm{kg}^{-1} \mathrm{~min}^{-1}$; or (iv) $5.0 \mu \mathrm{g}$ ritodrine $\mathrm{kg}^{-1}$ $\min ^{-1}$. All drug treatments increased the interval between pup deliveries compared with the no surgery and saline controls. Apparent complete tocolysis was observed in $20,60,80$ and $80 \%$ of the animals receiving $0 \cdot 5,1 \cdot 0$ or $2 \cdot 0 \mu \mathrm{g}$ nifedipine $\mathrm{kg}^{-1} \mathrm{~min}^{-1}$ or $5.0 \mu \mathrm{g}$ ritodrine $\mathrm{kg}^{-1} \mathrm{~min}^{-1}$, respectively. A positive pharmacodynamic relationship was observed for the nifedipine doses. Analysis of pup viability showed no statistically significant difference among treatments. Treatment with $2 \cdot 0 \mu \mathrm{g}$ nifedipine $\mathrm{kg}^{-1} \mathrm{~min}^{-1}$ gave a delay in pup delivery comparable to that with ritodrine.
\end{abstract}

Key'words: nifedipine; ritodrine; preterm labour; tocolysis; rat

\section{Introduction}

Preterm labour is associated with a high risk of morbidity and mortality to mother and fetus, and has significant medical costs. Only ritodrine has been approved by the US Food and Drug Administration for the treatment of premature labour, but it has undesirable side-effects (Benedetti, 1983), which have prompted researchers to explore the use of other agents for the treatment of preterm labour.

One agent currently under investigation is nifedipine, which is effective in delaying fetal delivery in humans (Ulmsten et al., 1984; Kaul et al., 1985; Read \& Wellby, 1986; Ferguson et al., 1989). Animal studies have been conducted using various models to study the effects of nifedipine on uterine contractions and the delivery process (Hahn et al., 1984; Golichowski et al., 1985; Abel \& Hollingsworth, 1985a,b, 1986). In all cases, nifedipine caused a significant reduction in the frequency or strength of uterine contractions or delayed delivery. Pharmacodynamic and preliminary toxicity profiles for nifedipine were not established in these studies. In preliminary studies, (Ferguson et al., 1989) sublingual and oral administration of nifedipine as tocolytic therapy delayed delivery in 11 of 13 human patients, wide variability in plasma concentrations being observed. Nifedipine was detected in five of 11 neonates studied. However, pharmacodynamic analyses comparing plasma concentration with degree of tocolysis have not been performed.

An animal model is therefore needed to establish pharmacodynamic and preliminary toxicity profiles for nifedipine and to compare these results with those for ritodrine. This study, using a rat model, evaluated the ability of nifedipine to delay delivery of pups and assessed associated drug plasma concentrations and pup survival rate.

\section{Materials and Methods}

\section{Model}

The study was based on a model developed by Hahn et al. (1984), which assessed the delay in delivery of a second pup after administration of nifedipine by an oral gavage technique. Modifications to this model were sought because

*Present address and reprint requests: Division of Clinical Pharmacology, Indiana University School of Medicine, 1001 W. 10th Street, Indianapolis, IN 46202, USA.

†Present address: Department of Pharmacy Practice, University of Toledo, Toledo, OH 43606, USA. 
of concerns that oral gavage may interfere with normal delivery and confound data interpretation. The Hahn et al. (1984) model did not provide for evaluating subsequent pup deliveries and so an intravenous system using a bolus dose followed by continuous infusion was chosen for drug administration to avoid bioavailability deviations and to attain steady-state nifedipine plasma concentrations immediately.

\section{Animals and mating}

All procedures were performed according to protocol established and approved by the Purdue University Animal Care and Use Committee. Wistar rats (300-350 g) were housed in group cages and allowed food and water ad libitum. The room was maintained at $22^{\circ} \mathrm{C}$ and $44-55 \%$ relative humidity with lights on at $07.00 \mathrm{~h}$ and off at $19.00 \mathrm{~h}$. During mating, one male was placed in a cage with three females and they remained together for 4 days. Female rats were weighed daily and those exhibiting significant $(>50 \mathrm{~g})$ and continuous weight gain 2 weeks after the cohabitation period were assumed pregnant and entered into the study protocol. The day of expected delivery was based on the assumption of a 23-day gestation period for rats.

\section{Treatment}

Three to five days before expected delivery, an intravenous catheter was inserted, following a procedure modified from Enrione et al. (1987): Intramedic ${ }^{\circledR}$ tubing was inserted into the left jugular vein and exited on the subscapular area of the back. The catheter tubing was attached to a Button Infuser ${ }^{\circledR}$ (Markwell Medical; normally intended for multiple insulin dosing in man) with an attached 27-gauge needle to allow a Luer-lock connection to the intravenous tubing. This catheter system was flushed twice a day with $0 \cdot 1-0 \cdot 2 \mathrm{ml}$ heparin $\left(100 \mathrm{units}^{-1}\right)$ to maintain patency.

Nifedipine and ritodrine solutions for intravenous administration were prepared on the day of expected delivery to minimize drug decomposition. Nifedipine powder $(10 \mathrm{mg})$ (Pfizer Laboratories, New York, USA) was dissolved in ethanol and glycerin and diluted to the proper concentration (to allow infusion at $1.5 \mathrm{ml} \mathrm{h}^{-1}$ ) with a sufficient volume of sterile water for injection. The final concentrations of ethanol and glycerin (both added to enhance nifedipine solubility) in all nifedipine infusion solutions were 3 and $10 \%$, respectively. Ritodrine $\mathrm{HCl}\left(10 \mathrm{mg} \mathrm{ml}^{-1}\right)(\mathrm{Astra}$ Pharmaceutical, Westboro, MA, USA) was diluted to the desired concentration using $0.9 \% \mathrm{NaCl}$ injection.

Five pregnant female rats were randomly assigned to each group and treated with $0 \cdot 25,0 \cdot 5,1 \cdot 0$ or $2 \cdot 0 \mu \mathrm{g}$ nifedipine $\mathrm{kg}^{-1} \mathrm{~min}^{-1} ; 5.0 \mu \mathrm{g}$ ritodrine $\mathrm{kg}^{-1} \mathrm{~min}^{-1}$ (the maximum dose approved by the US Food and Drug Administration) (appropriately adjusted for body weight), $0.9 \% \mathrm{NaCl}$ (control) or no treatment control. On day 23 after initiation of mating, the pregnant animals were observed continuously for signs of labour (overtly noticeable pup movement within the abdomen and/or vaginal bleeding). Immediately after delivery of the first pup, a bolus infusion was given to the nifedipine-treatment animals. Nifedipine kinetic parameters in rats (Testa et al., 1979) were used to predict steadystate concentrations and to calculate the bolus doses. The bolus infusion was administered over 1 min, followed by the appropriate continuous infusion at $1.5 \mathrm{ml} \mathrm{h}^{-1}$ using a syringe pump. Ritodrine and $0.9 \% \mathrm{NaCl}$ were also infused at $1.5 \mathrm{ml} \mathrm{h}^{-1}$, but no bolus dose was given for ritodrine infusions as this is not done clinically in humans and, therefore, no bolus was given for the saline-treated animals. Infusions were continued until all pups had been delivered or apparent complete tocolysis was suspected. In animals exhibiting a delay, but not a cessation, of deliveries, all pups were assumed to have been delivered if normal maternal activity had resumed and no pups had been delivered for $2 \mathrm{~h}$. During pilot studies, the validity of this was established and thus, allowing for variability, $2 \mathrm{~h}$ was chosen as the time for discontinuing therapy. The infusion was allowed to continue for $8 \mathrm{~h}$ in animals exhibiting immediate or nearimmediate complete tocolysis (zero to three pups delivered after therapy initiation). In the case of complete tocolysis, it was considered that, if delivery had been delayed for $8 \mathrm{~h}$, complete tocolysis had occurred and that normal delivery should be allowed to resume as it had been a considerable period since the maternal membranes had ruptured. Reversibility of effect was measured as ability of the rat to re-initiate pup delivery following apparent complete tocolysis and cessation of drug therapy for $8 \mathrm{~h}$.

The interval between each subsequent pup delivery following the first pup was measured for each animal. Plasma samples for nifedipine were obtained from the ophthalmic branch of the carotid artery via a capillary tube temporarily inserted into the periorbital space at $15 \mathrm{~min}$ after initiation of infusion and at the end of all deliveries (or after $8 \mathrm{~h}$ in animals exhibiting complete tocolysis) and frozen immediately at $-15^{\circ} \mathrm{C}$ until analysis. Pup viability was assessed as the number of pups remaining alive $6 \mathrm{~h}$ after delivery.

\section{Assay}

Nifedipine plasma concentrations were analysed using a procedure modified slightly from Kleinbloesem et al. (1984). This assay had a limit of sensitivity of $10 \mathrm{ng} \mathrm{ml}^{-1}$ and an intra-assay coefficient of variance of $4.58 \%$. All procedures were performed under controlled sodium lighting because nifedipine can photodecompose.

\section{Statistical analysis}

Data were analysed by one-way ANOva followed by Student-Newman-Keuls multiple comparison of means. 


\section{Results}

A statistically significant difference in interval between pup deliveries was observed between drugtreated and control rats (Table 1). Although these mean data did not appear to show a progressive dose-response curve, upon examination of the total data a graded response was seen comparing all nifedipine treatments and ritodrine treatments with the no-surgery and saline controls: $20,60,80$ and $80 \%$ of animals, treated with $0.5,1.0$ or $2 \cdot 0 \mu \mathrm{g}$ nifedipine $\mathrm{kg}^{-1} \mathrm{~min}^{-1}$ or $5.0 \mu \mathrm{g}$ ritodrine $\mathrm{kg}^{-1}$ $\min ^{-1}$, respectively, exhibited apparent complete tocolysis (defined as absence of pup delivery for $8 \mathrm{~h}$ following almost immediate cessation of deliveries after drug administration) whereas the animals in the other treatment groups did not show this effect. Because of the averaging procedure, the mean values for interval between pup delivery therefore became skewed, as this parameter was essentially without value in animals in whom tocolysis was exhibited. This resulted in the doses of 1.0 and $2.0 \mu \mathrm{g}$ nifedipine $\mathrm{kg}^{-1} \mathrm{~min}^{-1}$ and $5.0 \mu \mathrm{g}$ ritodrine $\mathrm{kg}^{-1} \mathrm{~min}^{-1}$ appearing to be less effective than $0.5 \mu \mathrm{g}$ nifedipine $\mathrm{kg}^{-1} \mathrm{~min}^{-1}$, when, in fact, they caused an immediate or nearly immediate cessation of pup delivery in three, four and four animals, respectively.

Table 1. Mean interval between pup deliveries and number of pups delivered during drug treatment in rats

\begin{tabular}{lccc}
\hline Treatment & $n$ & $\begin{array}{c}\text { Interval } \\
\text { between pups } \\
(\mathrm{min})\end{array}$ & $\begin{array}{c}\text { Number } \\
\text { delivered }\end{array}$ \\
\hline No surgery & 5 & $4 \cdot 4 \pm 0 \cdot 4$ & $13 \cdot 0 \pm 3 \cdot 5$ \\
Saline & 5 & $6 \cdot 7 \pm 1 \cdot 3$ & $12 \cdot 6 \pm 4 \cdot 9$ \\
Nifedipine & & & \\
$\left(\mu \mathrm{g} \mathrm{kg}^{-1} \mathrm{~min}^{-1}\right)$ & & & \\
$0 \cdot 25$ & 5 & $27 \cdot 4 \pm 21 \cdot 9^{*}$ & $8 \cdot 4 \pm 3 \cdot 0$ \\
$0 \cdot 5$ & 5 & $52 \cdot 9 \pm 2 \cdot 5^{*}$ & $5 \cdot 4 \pm 2 \cdot 5^{*}$ \\
$1 \cdot 0$ & 5 & $22 \cdot 4 \pm 10 \cdot 6^{*}$ & $4 \cdot 8 \pm 4 \cdot 5^{*}$ \\
$2 \cdot 0$ & 5 & $44 \cdot 4 \pm 37 \cdot 3^{*}$ & $2 \cdot 4 \pm 2 \cdot 1^{* \dagger}$ \\
Ritodrine & & & \\
$\left(\mu \mathrm{g} \mathrm{kg}^{-1} \min ^{-1}\right)$ & & $32 \cdot 3 \pm 22 \cdot 2^{*}$ & $2 \cdot 2 \pm 3 \cdot 9^{* \dagger}$ \\
$\quad 5 \cdot 0$ & 5 & $32 \cdot 3 \pm 2$ \\
\hline
\end{tabular}

Data are means \pm SD.

* Significantly different from controls $(P<0.05)$.

In these treatments, one to three pups were delivered before complete tocolysis occurred.

This 'false skewing' of the data can be partially resolved by comparing the mean number of pups delivered during drug treatment (Table 1). For $2 \mu \mathrm{g}$ nifedipine $\mathrm{kg}^{-1} \mathrm{~min}^{-1}$ and $5 \cdot 0 \mu \mathrm{g}$ ritodrine $\mathrm{kg}^{-1} \mathrm{~min}^{-1}$, the values include cases where one to three pups were born before complete tocolysis occurred. All drug treatments, except $0.25 \mu \mathrm{g}$ nifedipine $\mathrm{kg}^{-1} \mathrm{~min}^{-1}$, produced a statistically significant decrease in the mean number of pups delivered during drug treatment. There was a consistent decrease in the number of pups delivered during drug treatment (i.e. the remainder were delivered after $8 \mathrm{~h}$ of apparent drug-induced tocolysis with increasing doses of nifedipine or with ritodrine). This suggests a progressive effect in delaying and/or stopping pup delivery with an increase in drug dose. Theoretically, the randomization process should have balanced any differences in the total number of delivered pups and thus have no effect on the percentage of pups delivered during drug treatment. This was verified by there being no statistical difference in the total number of pups delivered in any of the treatment groups.

Plasma samples were obtained for the nifedipine treatments at $15 \mathrm{~min}$ after initiation of treatment and at the end of all deliveries or $8 \mathrm{~h}$ after apparent complete tocolysis. The best-fit line for the 
mean (of $15 \mathrm{~min}$ and end of all deliveries) plasma concentrations of nifedipine and their relationship with the corresponding overall mean interval between pup deliveries (Fig. 1) exhibits a correlation coefficient of 0.6721 , indicating a statistically significant positive pharmacodynamic correlation between the paired data sets. The mean nifedipine plasma concentration in animals exhibiting apparent complete tocolysis was $363 \cdot 1 \pm 187 \cdot 1 \mathrm{ng} \mathrm{ml}{ }^{-1}$, consistent with the pharmacodynamic relationship suggested in Fig. 1.

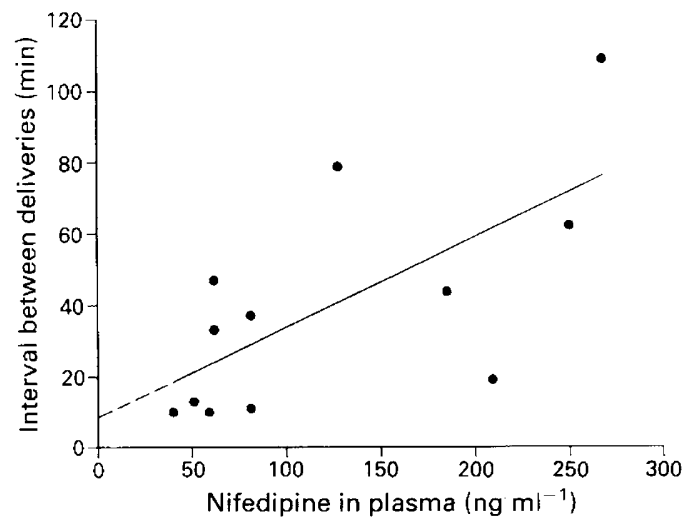

Fig. 1. Linear regression fit of pharmacodynamic properties of nifedipine in delaying pup delivery to rats: mean plasma concentration versus average interval between deliveries.

No distinction was made between pups stillborn and those dying after delivery, because it was impossible to distinguish between those stillborn due to natural causes and those stillborn due to drug treatment. Controls were treated in a similar manner to reduce any bias. Drug treatments produced a slightly lower percentage of viable pups delivered (Table 2) than did the controls, but these values were not statistically significant $(P>0 \cdot 25)$ after analysis by one-way ANOVA. In some cases, not all pups had been delivered (because of complete tocolysis) and the percentage viability for pups delivered during drug treatment and after drug treatment was therefore also measured (Table 2). In cases where this occurred, a $\chi^{2}$ analysis was performed to determine whether any differences existed: it showed overall differences in the proportions of viable pups delivered across treatment groups $(P<0.01)$. However, when each of these cases was analysed individually, using Student's $t$ test, no statistically significant difference was determined specific to any one of the treatments.

Table 2. Total percentage of viable pups delivered to rats

\begin{tabular}{|c|c|c|c|}
\hline Treatment & Total viable & During treatment & After treatment \\
\hline No surgery & $92 \cdot 6 \pm 5 \cdot 7$ & $92.6 \pm 5.7$ & $\mathrm{n} / \mathrm{a}$ \\
\hline Saline & $86 \cdot 9 \pm 21 \cdot 1$ & $86 \cdot 9 \pm 21 \cdot 1$ & $\mathrm{n} / \mathrm{a}$ \\
\hline \multicolumn{4}{|l|}{$\begin{array}{l}\text { Nifedipine } \\
\left(\mu \mathrm{g} \mathrm{kg}^{-1} \min ^{-1}\right)\end{array}$} \\
\hline 0.25 & $87 \cdot 4 \pm 14 \cdot 1$ & $87 \cdot 4 \pm 14 \cdot 1$ & $\mathrm{n} / \mathbf{a}$ \\
\hline 0.5 & $74.5 \pm 13.0$ & $75.4 \pm 23.6$ & $72 \cdot 8 \pm 28 \cdot 54^{*}$ \\
\hline 1.0 & $72.8 \pm 17.0$ & $67 \cdot 8 \pm 21 \cdot 0$ & $77 \cdot 0 \pm 24 \cdot 04^{*}$ \\
\hline $2 \cdot 0$ & $74 \cdot 1 \pm 17 \cdot 7$ & $91.7 \pm 16.7$ & $71 \cdot 7 \pm 23.04^{*}$ \\
\hline \multicolumn{4}{|l|}{$\begin{array}{l}\text { Ritodrine } \\
\left(\mu \mathrm{kg}^{-1} \min ^{-1}\right)\end{array}$} \\
\hline 5.0 & $77 \cdot 4 \pm 18 \cdot 0$ & $94.5 \pm 7.8$ & $66 \cdot 8 \pm 31 \cdot 14^{*}$ \\
\hline
\end{tabular}

Data are means \pm SD.

*Not statistically significantly different compared with percentages during treatment. n/a: not applicable. 


\section{Discussion}

This model for pregnant rats appears valid for evaluating the tocolytic response of nifedipine therapy compared with the clinical standard ritodrine and controls. Previous models have not been able to measure such factors as attenuation of effect, reversibility of effect and fetal viability, as was possible using this model. Hahn et al. (1984) developed a model measuring the time delay after drug administration by oral gavage until delivery of the second pup. Some uncertainty concerning the applicability of this model arises in that the mean interval between pups in the present study was $4.4 \pm 0.4$ min in nosurgery controls, whereas Hahn et al. measured a mean of approximately 16 min between pup deliveries in animals receiving vehicle (control treatment) via the oral gavage technique. The gavage technique may itself cause a physiological response that affects the interval between pups.

Abel \& Hollingsworth (1985a, b, 1986) used a model wherein rats received prophylactic tocolytic therapy after artificially induced labour. This model used ovariectomy with subsequent oestrogen therapy to induce uterine contractions and labour and then measured the number of pups remaining in utero (after killing the mother) after 3 days of treatment, thus giving no indication whether labour already in progress could be stopped or whether labour is reinitiated after ceasing tocolytic therapy.

The model for pregnant ewes used by Golichowski et al. (1985) does allow for the reinitiation of labour as well as haemodynamic monitoring, but again uses artificial induction of labour. Although such induction is more convenient for an investigator, in that the onset of labour can be controlled more accurately, it is uncertain whether this mimics the natural process of labour initiation. Thus, the model is not applicable to the clinical situation.

The pharmacodynamic activity of nifedipine appeared to provide a positively correlated response in delaying pup delivery relative to plasma concentration. The doses of nifedipine chosen for this research approximated the range $\left(\mu \mathrm{g} \mathrm{kg}^{-1}\right)$ currently administered to humans for approved use in alleviating angina pectoris (Nifedipine package insert, 1986). It therefore appears that tocolysis is an extension of the pharmacological activity of nifedipine in doses $\left(\mu \mathrm{g} \mathrm{kg}^{-1}\right)$ paralleling those used for the treatment of heart disease. Owing to the significant variability in the apparent pharmacokinetic traits among animals, as well as the onset of tocolysis, from these data a specific dose of nifedipine cannot be used as a target to achieve a particular tocolytic effect. However, the plasma concentration and corresponding tocolytic effect achieved with a given dose can be assessed with the expectation that an increase in dose will produce a graded, positive increase in effect. This type of pharmacodynamic relationship has been demonstrated for nifedipine in the treatment of angina pectoris, the effective plasma concentration of nifedipine varying from 20 to $150 \mathrm{ng} \mathrm{ml}^{-1}$ in patients (Chaitman et al., 1984). Ferguson et al. (1989) reported significant pharmacokinetic variability among 11 patients exhibiting delay of delivery after administration of nifedipine.

The complete tocolytic response to nifedipine was reversible and normal delivery could be reinitiated by the animal after discontinuation of nifedipine infusion, corroborating the findings of Ferguson et al. (1989). However, with continued infusion, the activity of nifedipine in delaying pup delivery appeared to attenuate when less than complete tocolysis was achieved. This attenuation of effect has been shown to occur also during ritodrine therapy (Johansson \& Andersson, 1981).

Pup viability was not statistically different across treatment groups. When complete tocolysis was achieved, pup viability was not statistically significantly different upon reinitiation of labour compared with that of pups delivered during drug administration before complete tocolysis. Care must be exercised in interpreting these viability data because of the small samples. However, Ahokas et al. (1988) recently showed that nifedipine does not adversely affect uteroplacental blood flow in hypertensive term-pregnant rats and Ferguson et al. (1989) reported no adverse effects on human neonates, despite detectable nifedipine concentrations in some neonates, adding support to the hypothesis that nifedipine does not cause fetal toxicity.

The results of this study confirm the tocolytic properties of nifedipine and partly delineate its pharmacodynamic and toxicity profiles. 
The technical assistance of P. Burns and M. Gray is gratefully acknowledged.

\section{References}

Abel, M.H. \& Hollingsworth, M. (1985a) Tolerance to salbutamol on the rat uterus in vivo compared with nifedipine and diltiazem (abst). British Journal of Pharmacology 85, 331P.

Abel, M.H. \& Hollingsworth, M. (1985b) The potencies and selectivities of four calcium antagonists as inhibitors of uterine contractions in the rat in vivo. British Journal of Pharmacology 85, 263-269.

Abel, M.H. \& Hollingsworth, M. (1986) Comparison of nifedipine and diltiazem with salbutamol for prevention of preterm delivery in the ovariectomized, oestrogen-treated late pregnant rat. Journal of Reproduction and Fertility 77, 559-568

Ahokas, R.A., Sibai, B.M., Mabie, W.C. \& Anderson, G.D. (1988) Nifedipine does not adversely affect uteroplacental blood flow in the hypertensive termpregnant rat. American Journal of Obstetrics and Gynecology 159, 1440-1445.

Benedetti, T.J. (1983) Maternal complications of parenteral beta-sympathomimetic therapy for premature labor. American Journal of Obstetrics and Gynecology $145,1-6$.

Chaitman, B.R., Wagniart, P., Pasternac, A., Brevers, G., Scholl, J.M. et al. (1984) Improved exercise tolerance after propranolol, diltiazem or nifedipine in angina pectoris: comparison at 1,3 and 8 hours and correlation with plasma drug concentration. American Journal of Cardiology 53, 1-9.

Enrione, E.B., Morre, D.M. \& Black, C.D. (1987) Carcass and organ composition of rats fed high total parenteral nutrition. Journal of Parenteral and Enteral Nutrition 11, 152-158.

Ferguson, J.E., Schutz, T., Pershe, R., Stevenson, D.K. \& Blaschke, T. (1989) Nifedipine pharmacokinetics during preterm labor tocolysis. American Journal of Obstetrics and Gynecology 161, 1485-1490.
Golichowski, A.M., Hathaway, D.R., Fineberg, N. \& Peleg, D. (1985) Tocolytic and hemodynamic effects of nifedipine in the ewe. American Journal of Obstetrics and Gynecology 151, 1134-1140.

Hahn, D.W., McGuire, J.L., Vanderhoof, M., Ericson, E. \& Pasquale, S.A. (1984) Evaluation of drugs for arrest of premature labor in a new animal model. American Journal of Obstetrics and Gynecology 148, 775-778.

Johansson, S.R.M. \& Andersson, R.G.G. (1981) Mechanisms of beta-adrenergic desensitization in rat myometrium. Acta Pharmacologica et Toxicologica 49, 241-247.

Kaul, A.F., Osathanondh, R., Safon, L.E., Frigoletto, F.D. \& Friedman, P.A. (1985) The management of preterm labor with the calcium channel-blocking agent nifedipine combined with the betamimetic terbutaline. Drug Intelligence and Clinical Pharmacy $19,369-371$.

Kleinbloesem, C.H., Van Harten, J., Van Brummelen, P. \& Breimer, D.D. (1984) Liquid chromatographic determination of nifedipine in plasma and of its main metabolite in urine. Journal of Chromatography and Biomedical Applications 308, 209-216.

Read, M.D. \& Wellby, D.E. (1986) The use of a calcium antagonist (nifedipine) to suppress preterm labour. British Journal of Obstetrics and Gynecology 93, 933-937.

Testa, R., Dolfini, E., Reschiotto, C., Secchi, C. \& Biondi, P.A. (1979) GLC determination of nifedipine, a light sensitive drug, in plasma. Il Farmaco 34, 463-473.

Ulmsten, U., Andersson, K.-E. \& Wingerup, L. (1984) Treatment of hypertensive patients with preterm labor using oral nifedipine, a calcium antagonist. Archives of Gynecology 236, 69-72.

Received 11 February 1991 